\title{
A study of the opinions of Swedish healthcare personnel regarding acceptable outcome following decompressive hemicraniectomy for ischaemic stroke
}

\author{
Magnus Olivecrona $^{1}$ (D) $\cdot$ Stephen Honeybul ${ }^{2}$
}

Received: 26 June 2017 / Accepted: 7 October 2017 /Published online: 4 November 2017

(C) The Author(s) 2017. This article is an open access publication

\begin{abstract}
Background Decompressive hemicraniectomy (DC) is an established lifesaving treatment for malignant infarction of the middle cerebral artery (mMCAI). However, surgical decompression will not reverse the effects of the stroke and many survivors will be left severely disabled. The objective of this study was to assess what neurological outcome would be considered acceptable in these circumstances amongst Swedish healthcare workers.

Method Healthcare workers were invited to participate in a presentation that outlined the pathophysiology of mMCAI, the rationale behind DC and outcome data from randomised controlled trials that have investigated efficacy of the procedure. They were then asked which neurological outcome would they feel to be acceptable based on the modified Rankin Score (mRS) and the Aphasia Handicap Scale (AHS). Information regarding sex, age, marital status, relatives, religion, earlier experience of stroke and occupation was also collected.

Results Six hundred and nine persons participated. The median accepted $\mathrm{mRS}$ was 3 . An $\mathrm{mRS}$ of 4 or 5 was perceived to be acceptable by only $30.5 \%$ of participants. Therefore the most likely outcome, based on the results of the randomised controlled trials, would be unacceptable to most of the participants [OR 0.39 (CI, 0.22-0.69)]. The median accepted AHS
\end{abstract}

Magnus Olivecrona

Magnus.olivecrona@oru.se

1 Department of Anaesthesia and Intensive Care, Section for Neurosurgery, Faculty of Health and Medicine, Department for Medical Sciences, Örebro University, Örebro, Sweden

2 Departement of Neurosurgery, Sir Charles Gairdner Hospital, Perth, WA, Australia was 3. A worst language outcome of restricted autonomy of verbal communication (AHS 3) or better would be accepted by $44.6 \%$.

Conclusions This study has highlighted the ethical problems when obtaining consent for DC following MMCAI, because for many of the participants the most likely neurological outcome would be deemed unacceptable. These issues need to be considered prior to surgical intervention and the time may have come for a broader societal discussion regarding the value of a procedure that converts death into survival with severe disability given the attendant financial and healthcare resource implications.

Keywords Malignant middle cerebral artery infarction . Hemicraniectomy $\cdot$ Outcome $\cdot$ Ethics

\section{Introduction}

The past decade has seen considerable advances in the management of ischaemic stroke and a number of clinical trials have demonstrated the significant reduction in mortality and improvement in outcome that can be achieved by endovascular techniques using either intra-arterial therapy or mechanical thrombectomy $[1,5,9]$. However, the timedependent nature of these interventions means that there will always be patients who either present outside the therapeutic window or for whom endovascular therapy fails.

Approximately $1-10 \%$ of these patients will go on to develop life-threatening cerebral oedema, so called "malignant" middle cerebral artery infarction (mMCAI) and the prognosis for these patients is poor with a mortality rate in the region of $80 \%$. In these circumstances, consideration may be given to decompressive craniectomy as a lifesaving intervention. One of the first descriptions of the technique was from Professor 
Koch in 1905 and he asserted that "if there is no CSF pressure, but brain pressure exists, then pressure relief must be achieved by opening the skull" [19]. The rationale for surgical decompression is that death due to tonsillar herniation is prevented and the reduction in mortality has been clearly demonstrated by recent randomised controlled trials [10, 17, 18, 25, 26]. However, unlike the endovascular techniques, surgical decompression will not reverse the effects of what is by definition a very extensive infarct and many patients will be left with significant neurological deficits $[15,24]$. Indeed, in the pooled analysis of the three European stroke trials, it was only possible to conclude that surgery improved clinical outcome by redefining the favourable category such that it included patients with a modified Rankin Scale (mRS) of 4 [25]. Favourable outcome would, therefore, include patients who could not walk unaided, could not look after their bodily needs and were, therefore, dependent. To justify this recategorisation, the authors have stated that "On the basis of increasing experience of long-term outcome in patients with a space-occupying infarction, most investigators feel obliged to define a score of 4 on the modified Rankin scale (mRS) as favourable". However, closer examination of the literature shows little evidence to support this statement [13].

The aim of this study was to canvass opinion amongst healthcare workers in Sweden regarding the acceptable outcome in terms of mRS and assess opinion regarding the importance of language preservation.

\section{Methods}

Staff in the Departments of Neurology, Anaesthesiology and Intensive Care (ANICU) and Cardiology at the University Hospital in Örebro, Sweden were invited to participate in the study during one of their annual education days. Participants were presented with information regarding the pathophysiology of mMCAI and the expected mortality if untreated. This included an introduction to basic concepts such as the Monroe Kellie doctrine and the role of DC as a lifesaving intervention. It was emphasised that surgery would not reverse the effects of the stroke but would certainly reduce mortality. The results of recent randomised controlled trials were presented in order to inform participants of the most likely outcome following surgical intervention when compared to standard medical therapy. The need for informed consent and the regulatory requirements in Sweden was also was presented. The aim of the presentation was to provide unbiased evidence regarding outcome in a similar manner to which this type of information is conveyed to patients and their relatives. After the presentation, participants were given the opportunity to ask questions. They were then asked which functional level in terms of mRS they would accept if they were to survive following DC for mMCAI (Table 1) [8].
The questionnaire was similar to that used by Honeybul et al. [14] in a previous study. (Questionnaire available as supplemental data.) There were modifications in that there were additional questions concerning the acceptability of language deficits according to the Aphasia Handicap Scale (AHS), ranging from 0 to 5 (Table 2) [2]. Additional information regarding sex, age, marital status, relatives, religion, earlier experience of stroke and occupation was also collected.

\section{Statistics}

Continuous and categorical data are presented as numbers and percentages and interquartile range. Differences between groups were analysed by $\chi^{2}$ tests, as indicated. The statistical analysis was performed with JMP ver. 12 (SAS Institute, Cary, $\mathrm{NC}$, USA). A $p$ value of $<0.05$ was considered as statistically significant.

\section{Ethics}

The Regional Ethical Review Board in Uppsala has decided that the study does not need ethical review (Dnr 2014/451).

\section{Results}

Six hundred and nine persons answered the questionnaire. The characteristics of the persons are presented in Table 3.

The distribution of the highest accepted mRS (worst function) is illustrated in Fig. 1. The median acceptable mRS was 3 (IQR 1). The distribution of the highest accepted (worst function) AHS is illustrated in Fig. 2. The median acceptable AHS was 3 (IQR 2).

There was significant difference between the sexes in regard to the worst accepted functional outcome (mRS) (Pearson's $\chi^{2}, p<0.05$ ). Males seemed to accept a worse functional outcome compared to the females. There was no significant difference between the sexes with regard to accepted language disturbance (Pearson's $\chi^{2}, p=0.07$ ). No significant difference was found in analysing accepted worse outcome of mRS or AHS in relation to age, marital status, relatives, religion, earlier experience of stroke, profession or department.

Analysing the dichotomisation of mRS in $0-3[n=420$ $(69.5 \%)]$ and $4-5(n=184)$ significantly more participants would accept a mRS of 3 compared with those who would accept an outcome of mRS 4-5 $\left(\chi^{2}, p<0.001\right)$. There were no significant differences with regard to sex, age, marital status, relatives, religion, earlier experience of stroke, profession, or department.

The odds ratio (OR) for the investigated population to reach the most likely outcome based on the results of the three randomised studies (excluding mortality as the question asked 
Table 1 Modified Rankin Scale [9]

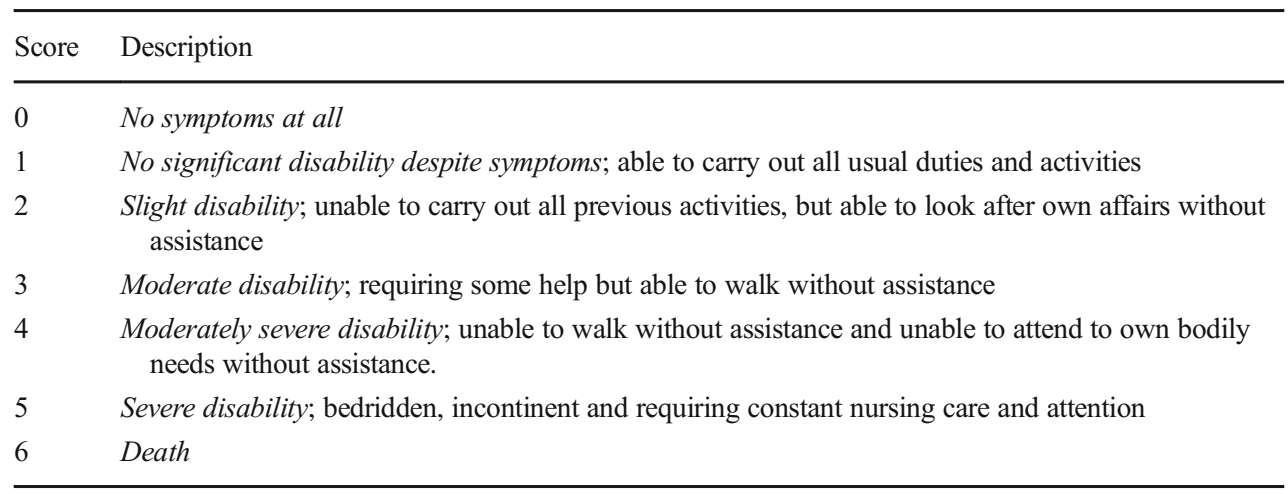

in the study specified survival) (see Table 4). The OR was 0.39 (95\% CI, 0.22-0.69) and the number needed to harm 3.1.

If the dichotomisation was made between mRS 0-4 $(n=580)$ and $\mathrm{mRS} 5(n=24)$, there is was significant difference amongst the sexes. Males accepted an mRS of 5 more often than females (Fisher's exact test $p<0.05$ ). There was no significant difference in terms of age, marital status, relatives, religion, earlier experience of stroke or profession.

Doing the dichotomisation of AHS in $0-3(n=432)$ and 4 5 ( $n=175)$, a significant difference is found between the sexes. Males would accept a worse AHS score than females (Fisher's exact test, 0.005). There was no significant difference found between the two groups with regards; age, marital status, relatives, religion, earlier experience of stroke, profession or department. When dichotomising between AHS of 0 $4(n=521)$ and $5(n=86)$, the same significant difference was found between the sexes (Fisher's exact test, 0.27); however, no other significant differences were found.

\section{Discussion}

The results of the recently published randomised controlled trials clearly demonstrate that surgical decompression significantly reduces mortality; however, this results in an almost direct translation into the number of survivors with a mRS of $4[10,17,25,26]$. Whilst the investigators in these studies changed the outcome dichotomy such that this outcome was deemed to be favourable, the results of this study would call this recatagorisation into question.

Indeed, based on the results of the trials and the responses of participants in this study, approximately every third person who survives following a DC for mMCAI (risk to harm 3.1) would do so with a level of disability that beforehand they would have felt to be unacceptable.

These findings are in concordance with a similar investigation performed amongst Australian healthcare workers in which only $8.7 \%$ of participants regarded an mRS of 4 5 as acceptable [14]. There were similar finding in a survey that assessed opinion in an online survey amongst North American and Asian neurologists, neurosurgeons and neurointensivists [22], and in a study that investigated opinion in patients who had previously suffered a stroke (and presumably thereby has first-hand experience of the consequences of stroke). Most respondents felt that survival with dependency (mRS of 4-5) would be unacceptable [23].

Overall, the results of these studies, in conjunction with the current study, would appear to provide compelling evidence that considering an mRS of $\geq 4$ as acceptable must at the very least be called into question or perhaps recategorised back to unacceptable. However, even if this were to occur, there remain questions regarding the ongoing use of DC given the clear reduction in mortality and there are a number of issues that require consideration.
Table 2 Aphasia Handicap Scale [2]

\begin{tabular}{ll}
\hline Score & Description \\
\hline 0 & Normal language \\
1 & Minor difficulties of language without disability (no impact on normal life) \\
2 & Mild language-related disability (without restrictions in the autonomy of verbal communication in daily \\
& life) \\
3 & Moderate language-related disability (restricted autonomy of verbal communication) \\
5 & Severe language-related disability (lack of effective verbal communication) \\
\hline
\end{tabular}


Table 3 Characteristics of the 609 participants

\begin{tabular}{|c|c|c|}
\hline Variable ( $n=$ number of answers) & & $n(\%)$ \\
\hline \multirow[t]{2}{*}{$\operatorname{Sex}(n=603)$} & Female & $505(83.2)$ \\
\hline & Male & $98(16.2)$ \\
\hline \multirow{6}{*}{$\begin{array}{l}\text { Age groups, } \\
\text { years }(n=601)\end{array}$} & $18-25$ & $24(4)$ \\
\hline & $25-35$ & $107(17.8)$ \\
\hline & $35-45$ & $139(23.1)$ \\
\hline & $45-55$ & $170(28.3)$ \\
\hline & $55-65$ & $154(25.6)$ \\
\hline & $65-$ & $7(1.2)$ \\
\hline \multirow[t]{3}{*}{$\begin{array}{l}\text { Marital status } \\
\qquad(n=606)\end{array}$} & $\begin{array}{l}\text { Married / common- } \\
\text { law partner }\end{array}$ & $462(76.2)$ \\
\hline & Single & $108(17.8)$ \\
\hline & Divorced & $36(5.9)$ \\
\hline \multirow[t]{5}{*}{ Relatives $(n=597)$} & None & $14(2.3)$ \\
\hline & Only children & $71(11.9)$ \\
\hline & Only parents & $16(2.7)$ \\
\hline & Only Siblings & $9(1.5)$ \\
\hline & $\begin{array}{l}\text { More than one } \\
\text { category }\end{array}$ & $487(81.6)$ \\
\hline \multirow{4}{*}{$\begin{array}{l}\text { Religion } \\
\qquad(n=589)\end{array}$} & Christianity & $312(53.0)$ \\
\hline & None & $238(40.4)$ \\
\hline & Will not state & $18(3.1)$ \\
\hline & Islam & $9(1.5)$ \\
\hline \multirow{4}{*}{$\begin{array}{l}\text { Experience of } \\
\quad \text { stroke }(n=601)\end{array}$} & None & $42(7.0)$ \\
\hline & $\begin{array}{l}\text { As a healthcare } \\
\text { worker }\end{array}$ & $433(72.0)$ \\
\hline & Relative & $253(42.1)$ \\
\hline & Acquaintance & $154(25.6)$ \\
\hline \multirow[t]{5}{*}{ Profession $(n=571)$} & Floor nurse & $112(19.6)$ \\
\hline & Registered nurse & $338(59.2)$ \\
\hline & Physician & $74(13.0)$ \\
\hline & Physiotherapist & $18(3.2)$ \\
\hline & Other & $29(5.1)$ \\
\hline
\end{tabular}

\section{Consent}

Informed consent forms one of the fundamental tenets of modern medicine. This requires that a competent person, given a clear understanding of the facts, implications and future consequences of an action, makes a decision prior to any intervention based on what they perceive to be an acceptable outcome, given their personal values $[3,4,6]$. In the context of a clinical deterioration following an acute stroke these requirements are challenged because the patient will be in no position to make competent judgements regarding their healthcare preferences and in these circumstances family members are often called upon to provide support for the decision to surgically intervene. This can place enormous psychological burden on relatives who are already distressed due to the impact of the initial illness and it is in this regard that the results of this

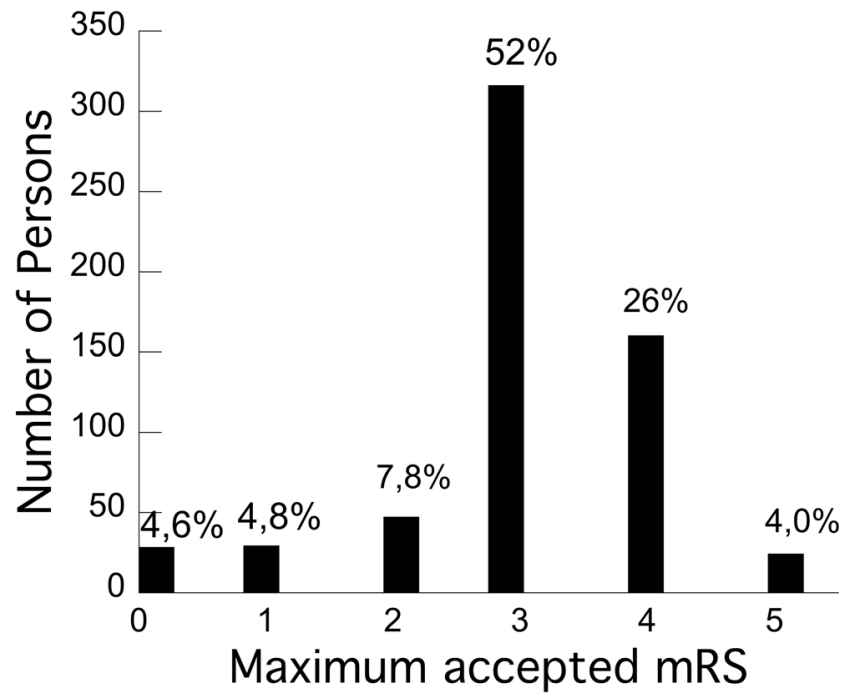

Fig. 1 Distribution of worst accepted functional outcome after decompressive craniectomy for malignant media infarction, measured as $\mathrm{mRS}$

type of study may be useful, not least because it may promote discussion in the wider community regarding these issues.

Although it could of course be argued that the circumstances in which participants were placed represented a relatively hypothetical situation that is not truly representative of the real live ethical tension that occurs in the context of an acute hemispheric stroke. It could equally be argued that in the real life clinical setting decisions have to be made under pressure of limited time and perhaps limited competency (due to emotional distress) to fully reflect on the long-term implications.

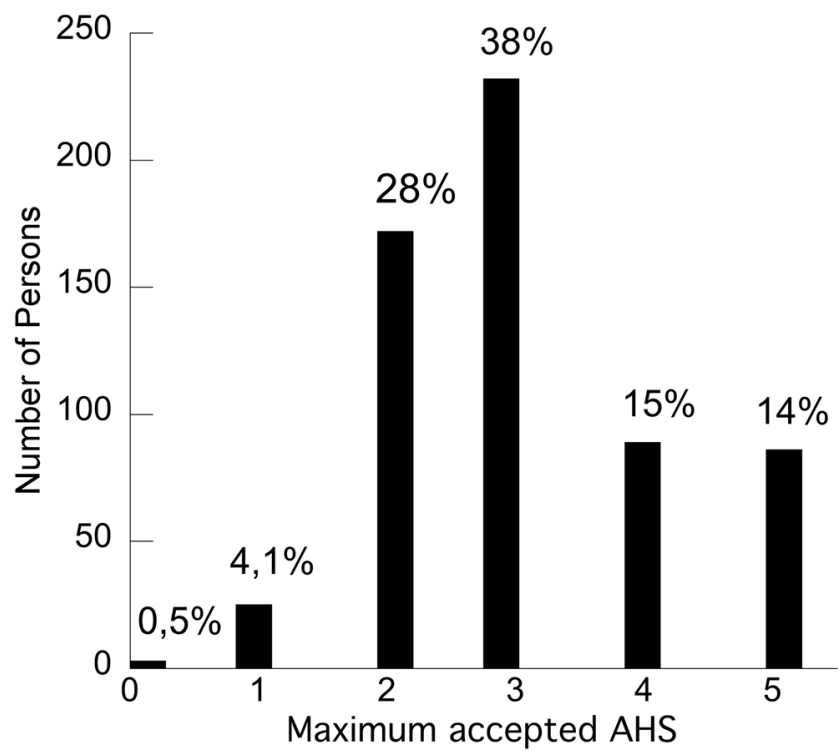

Fig. 2 Distribution of worst accepted outcome in regard to language disturbance after decompressive craniectomy for malignant media infarction, measured as AHS 
Table 4 Results as mRS in the three randomised trials

mRS 2 mRS 3 mRS 4 mRS 5 mRS 6 Total

\begin{tabular}{lllllll}
\hline Jüttler et al. [19] & 4 & 4 & 5 & 1 & 3 & 17 \\
Vahedie et al. [28] & 3 & 7 & 5 & 0 & 5 & 20 \\
Hofmeijer et al. [11] & 1 & 7 & 11 & 6 & 7 & 32 \\
Total & 8 & 18 & 21 & 7 & 15 & 69 \\
$\mathrm{mRS} \leq 3$ & 26 & & & & & \\
$\mathrm{mRS} \leq 4$ & 47 & & & & & \\
\hline
\end{tabular}

There is, however, no doubt that the circumstances in which participants were placed fulfils the criteria for truly informed consent, in that the implications of the intervention and likely outcome were fully explained and were competent to make an assessment regarding what they would feel to be an acceptable outcome $[6,7]$. Notwithstanding some limitations when making somewhat abstract observations such as "I would never want to live with severe disability", this type of assessment forms the basis of documentation such as living wills and advance directives. If a person has previously made their wishes known, either voiced or documented, regarding the acceptability or otherwise of survival with dependency these wishes should be acknowledged and where possible acted upon.

Based on this study, it would appear problematic to include an mRS of 4 within the outcome category of favourable and considerable caution must be exercised when this is going to be the most likely outcome (such as in patients over 60 years of age).

\section{Retrospective consent}

It must be acknowledged that humans are highly adaptable and can learn to live with a level of disability that they might previously thought to be unacceptable. Studies that have investigated the issue of retrospective consent provide support for this position. Indeed, the authors of the pooled analysis of the three European trials, justified the inclusion of an mRS of 4 within the favourable outcome category, because they obtained positive responses when they asked survivors whether they regretted having had the surgery, given they had survived, but remained disabled [25].

Furthermore, it would be difficult to state that it has not been in a person's best interests if they survive a neurological catastrophe but are able to state that they do not regret the intervention given their eventual quality of life. However, accepting this as a variation of the consenting process and, therefore, justifying the surgical procedure is not only ethically problematic but it also challenges the aforementioned necessity of informed consent prior to medical intervention. A more realistic interpretation of these responses is that these patients may have adapted to a level of disability that they might previously have deemed to be unacceptable and "recalibrated" their lifestyle expectations [16, 20].

A further consideration is that not all studies have obtained such high levels of retrospective consent, especially amongst the elderly. A number of studies have reported high levels of anxiety and depression, especially amongst survivors who have been left dependent $[11,21]$. The recent DESTINY II trial that investigated efficacy of DC in patients over 60 years of age reinforced this observation [18]. Notwithstanding the investigators conclusion that "hemicraniectomy increased survival without severe disability", most survivors were dependent and unable to communicate. Amongst those patients randomised to the surgical arm of the trial, there were 27 survivors. Two patients of those achieved an mRS score of 3. Of the remaining 25 patients, there was an equal distribution of patients between an mRS of 4 and 5 , and 16 of these patients had such severe aphasia or neuropsychological deficits that they were unable to provide a response regarding retrospective consent $[17,20]$.

These findings have in many ways undermined the legitimacy of retrospective consent and served to emphasise the need for significant discussion to occur prior to surgical intervention especially for persons in this age group [17].

\section{Language preservation}

The issue of language preservation and surgical decompression in the context of dominant hemispheric stroke has been a source of debate for many years. A surprising finding in this study is that $67 \%$ of participants would accept restricted verbal communication (i.e. AHS 3 or worse).

This is a similar finding to that of a previous study that has investigated opinion amongst stroke victims and their families, where it was found that amongst patients who had previously had a stroke, $52 \%$ would agree to a DC if the mMCAI was in the dominant hemisphere [23]. However, the interesting and perhaps more surprising finding is that if the mMCAI was in the non-dominant hemisphere only $42 \%$ would agree to have a DC. It is difficult to know how these findings should be interpreted, and it may be that language function and communication are not felt to as important as has previously been thought. The problem will always be how to determine the acceptability or otherwise of survival with severe speech difficulties as patients are often unable or have difficulty communicating their preferences. This was clearly demonstrated in the DESTINY II trial, in which most survivors could not answer a simple question regarding retrospective consent and would not therefore be in position to discuss more complex issues regarding quality of life. 


\section{Cultural issues and possible bias}

Finally, this study has demonstrated the wide range of responses that individuals provide and highlighted possible cultural differences that require consideration. In the current study, approximately $30 \%$ of participants within the Swedish healthcare system felt that survival with an mRS of 4 to be acceptable. Amongst Australian healthcare workers, only $10 \%$ would accept this outcome [14]. These differences may be based on current clinical practice within the particular healthcare environment in which the participants were involved or on socioeconomic factors. Both the current study and the Australian study failed to demonstrate any difference in responses based on religious orientation; however, there may be more subtle cultural influences and this would be an interesting aspect to explore further.

It must of course be acknowledged that there is potential for personal bias to influence the manner in which the data are presented and therefore interpreted by the participants. The senior author of the Australian study (S.H.) has frequently expressed a view that survival with an mRS of 4 should be categorised as unfavourable and this may (even unintentionally) have influenced the participants to give a negative response regarding this outcome [12, 15]. Alternatively, the higher response in the current study may reflect cultural values intrinsic to the Swedish society where survival at any cost may be felt to be important.

\section{Conclusions}

Overall there will never be a one-size-fits-all approach to the difficult ethical issues that require consideration when considering an intervention that potentially converts death into survival with dependency. The decision to surgically intervene requires consideration not only of personal preferences but also regarding the significant health resource implications that will arise whether it be in the context of ischemic stroke or for other neurological catastrophes. The time may have come for a broader discussion regarding the value placed on survival for any one individual at any cost, and the considerations here are not only financial but also ethical and moral regarding sustainable and equitable allocation of scarce healthcare resources.

Acknowledgements We thank the Departments of Neurology, Anaesthesia and Intensive Care, and Cardiology at the Örebro University Hospital for giving us the opportunity to perform this investigation during their education day. We also thank the persons answering the questionnaire for their participation.

Funding No funding was received for this research.

Compliance with ethical standards

Conflicts of interest None.
Ethics approval The Regional Ethical Review Board in Uppsala has decided that the study did not require ethical review (Dnr 2014/451).

Open Access This article is distributed under the terms of the Creative Commons Attribution 4.0 International License (http:// creativecommons.org/licenses/by/4.0/), which permits unrestricted use, distribution, and reproduction in any medium, provided you give appropriate credit to the original author(s) and the source, provide a link to the Creative Commons license, and indicate if changes were made.

\section{References}

1. Al-Ajlan FS, Goyal M, Demchuk AM, Minhas P, Sabiq F, Assis Z, Willinsky R, Montanera WJ, Rempel JL, Shuaib A, Thornton J, Williams D, Roy D, Poppe AY, Jovin TG, Sapkota BL, Baxter BW, Krings T, Silver FL, Frei DF, Fanale C, Tampieri D, Teitelbaum J, Lum C, Dowlatshahi D, Shankar JJ, Barber PA, Hill MD, Menon BK, Investigators ET (2016) Intra-arterial therapy and post-treatment infarct volumes: insights from the ESCAPE randomized controlled trial. Stroke 47:777-781

2. Azuar C, Leger A, Arbizu C, Henry-Amar F, Chomel-Guillaume S, Samson Y (2013) The aphasia rapid test: an NIHSS-like aphasia test. J Neurol 260:2110-2117

3. Beauchamp TL, Childress JF (2001) The capacity for autnomous choice. Principles of biomedical ethics. Oxford University Press, New York, pp 69-77

4. Beauchamp TL, Childress JF (2001) The meaning and justification of informed consent. Principles of biomedical ethics. Oxford University Press, New York, pp 77-103

5. Berkhemer OA, Fransen PS, Beumer D, van den Berg LA, Lingsma HF, Yoo AJ, Schonewille WJ, Vos JA, Nederkoorn PJ, Wermer MJ, van Walderveen MA, Staals J, Hofmeijer J, van Oostayen JA, Lycklama a Nijeholt GJ, Boiten J, Brouwer PA, Emmer BJ, de Bruijn SF, van Dijk LC, Kappelle LJ, Lo RH, van Dijk EJ, de Vries J, de Kort PL, van Rooij WJ, van den Berg JS, van Hasselt BA, Aerden LA, Dallinga RJ, Visser MC, Bot JC, Vroomen PC, Eshghi O, Schreuder TH, Heijboer RJ, Keizer K, Tielbeek AV, den Hertog HM, Gerrits DG, van den Berg-Vos RM, Karas GB, Steyerberg EW, Flach HZ, Marquering HA, Sprengers ME, Jenniskens SF, Beenen LF, van den Berg R, Koudstaal PJ, van Zwam WH, Roos YB, van der Lugt A, van Oostenbrugge RJ, Majoie CB, Dippel DW, Investigators MC (2015) A randomized trial of intraarterial treatment for acute ischemic stroke. $\mathrm{N}$ Engl $\mathrm{J}$ Med 372:11-20

6. Druml C (2004) Informed consent of incapable (ICU) patients in Europe: existing laws and the EU directive. Curr Opin Crit Care 10: $570-573$

7. Dunn LB, Nowrangi MA, Palmer BW, Jeste DV, Saks ER (2006) Assessing decisional capacity for clinical research or treatment: a review of instruments. Am J Psychiatry 163:1323-1334

8. Farrell B, Godwin J, Richards S, Warlow C (1991) The United Kingdom transient ischaemic attack (UK-TIA) aspirin trial: final results. J Neurol Neurosurg Psychiatry 54:1044-1054

9. Goyal M, Demchuk AM, Menon BK, Eesa M, Rempel JL, Thornton J, Roy D, Jovin TG, Willinsky RA, Sapkota BL, Dowlatshahi D, Frei DF, Kamal NR, Montanera WJ, Poppe AY, Ryckborst KJ, Silver FL, Shuaib A, Tampieri D, Williams D, Bang OY, Baxter BW, Burns PA, Choe H, Heo JH, Holmstedt CA, Jankowitz B, Kelly M, Linares G, Mandzia JL, Shankar J, Sohn SI, Swartz RH, Barber PA, Coutts SB, Smith EE, Morrish WF, Weill A, Subramaniam S, Mitha AP, Wong JH, Lowerison MW, Sajobi TT, Hill MD, Investigators ET (2015) Randomized 
assessment of rapid endovascular treatment of ischemic stroke. $\mathrm{N}$ Engl J Med 372:1019-1030

10. Hofmeijer J, Kappelle LJ, Algra A, Amelink GJ, van Gijn J, van der Worp HB, investigators H (2009) Surgical decompression for space-occupying cerebral infarction (the hemicraniectomy after middle cerebral artery infarction with life-threatening edema trial [HAMLET]): a multicentre, open, randomised trial. Lancet Neurol 8:326-333

11. Holtkamp M, Buchheim K, Unterberg A, Hoffmann O, Schielke E, Weber JR, Masuhr F (2001) Hemicraniectomy in elderly patients with space occupying media infarction: improved survival but poor functional outcome. J Neurol Neurosurg Psychiatry 70:226-228

12. Honeybul S, Gillett GR, Ho K (2013) Futility in neurosurgery: a patient-centered approach. Neurosurgery 73:917-922

13. Honeybul S, Ho KM (2013) The current role of decompressive craniectomy in the management of neurological emergencies. Brain Inj 27:979-991

14. Honeybul S, Ho KM, Blacker DW (2016) ORACLE stroke study: opinion regarding acceptable outcome following decompressive hemicraniectomy for ischemic stroke. Neurosurgery 79:231-236

15. Honeybul S, Ho KM, Gillett G (2015) Outcome following decompressive hemicraniectomy for malignant cerebral infarction: ethical considerations. Stroke 46:2695-2698

16. Honeybul S, Janzen C, Kruger K, Ho KM (2013) Decompressive craniectomy for severe traumatic brain injury: is life worth living? J Neurosurg 119:1566-1575

17. Juttler E, Schwab S, Schmiedek P, Unterberg A, Hennerici M, Woitzik J, Witte S, Jenetzky E, Hacke W, Group DS (2007) Decompressive surgery for the treatment of malignant infarction of the middle cerebral artery (DESTINY): a randomized, controlled trial. Stroke 38:2518-2525

18. Juttler E, Unterberg A, Woitzik J, Bosel J, Amiri H, Sakowitz OW, Gondan M, Schiller P, Limprecht R, Luntz S, Schneider H, Pinzer T, Hobohm C, Meixensberger J, Hacke W, Investigators DI (2014) Hemicraniectomy in older patients with extensive middle-cerebralartery stroke. N Engl J Med 370:1091-1100
19. Kocher T (1901) Die Therapie des Hirndruckes. In: Nothnagel A (ed) Hirnerschütterung, Hirndruck und chirurgische Eingriffe bei Hirnkrankheiten. A Hölder, Wien, pp 255-266

20. Larach DR, Larach DB, Larach MG (2009) A life worth living: seven years after craniectomy. Neurocrit Care 11:106-111

21. Leonhardt G, Wilhelm H, Doerfler A, Ehrenfeld CE, Schoch B, Rauhut F, Hufnagel A, Diener HC (2002) Clinical outcome and neuropsychological deficits after right decompressive hemicraniectomy in MCA infarction. J Neurol 249:1433-1440

22. Neugebauer H, Creutzfeldt CJ, Hemphill JC 3rd, Heuschmann PU, Juttler E (2014) DESTINY-S: attitudes of physicians toward disability and treatment in malignant MCA infarction. Neurocrit Care 21:27-34

23. Neugebauer H, Schnabl M, Lule D, Heuschmann PU, Juttler E, Group IS (2017) Attitudes of patients and relatives toward disability and treatment in malignant MCA infarction. Neurocrit Care 26: 311-318

24. Puetz V, Campos CR, Eliasziw M, Hill MD, Demchuk AM, Calgary Stroke P (2007) Assessing the benefits of hemicraniectomy: what is a favourable outcome? Lancet Neurol 6:580

25. Vahedi K, Hofmeijer J, Juettler E, Vicaut E, George B, Algra A, Amelink GJ, Schmiedeck P, Schwab S, Rothwell PM, Bousser MG, van der Worp HB, Hacke W, Decimal D, investigators H (2007) Early decompressive surgery in malignant infarction of the middle cerebral artery: a pooled analysis of three randomised controlled trials. Lancet Neurol 6:215-222

26. Vahedi K, Vicaut E, Mateo J, Kurtz A, Orabi M, Guichard JP, Boutron C, Couvreur G, Rouanet F, Touze E, Guillon B, Carpentier A, Yelnik A, George B, Payen D, Bousser MG, Investigators D (2007) Sequential-design, multicenter, randomized, controlled trial of early decompressive craniectomy in malignant middle cerebral artery infarction (DECIMAL trial). Stroke 38: 2506-2517 